\title{
Food Security and Nutritional Outcomes among Urban Poor Orphans in Nairobi, Kenya
}

\author{
Elizabeth W. Kimani-Murage, Penny A. Holding, \\ Jean-Christophe Fotso, Alex C. Ezeh, Nyovani J. Madise, \\ Elizabeth N. Kahurani, and Eliya M. Zulu
}

\begin{abstract}
The study examines the relationship between orphanhood status and nutritional status and food security among children living in the rapidly growing and uniquely vulnerable slum settlements in Nairobi, Kenya. The study was conducted between January and June 2007 among children aged 6-14 years, living in informal settlements of Nairobi, Kenya. Anthropometric measurements were taken using standard procedures and $z$ scores generated using the NCHS/WHO reference. Data on food security were collected through separate interviews with children and their caregivers, and used to generate a composite food security score. Multiple regression analysis was done to determine factors related to vulnerability with regards to food security and nutritional outcomes. The results show that orphans were more vulnerable to food insecurity than non-orphans and that paternal orphans were the most vulnerable orphan group. However, these effects were not significant for nutritional status, which measures long-term food deficiencies. The results also show that the most vulnerable children are boys, those living in households with lowest socioeconomic status, with many dependants, and female-headed and headed by adults with low human capital (low education). This study provides useful insights to inform policies and practice to identify target groups and intervention programs to improve the welfare of orphans and vulnerable children living in urban poor communities.
\end{abstract}

KEYWORDS Orphans, Vulnerable children, Urban poor, Food security, Nutritional outcomes, Kenya, Sub-Saharan Africa

\section{INTRODUCTION}

Despite being highlighted as one of the priority development issues under the Millennium Development Goals framework, malnutrition remains an important public health concern in the developing world. ${ }^{1}$ Nutritional status and food security

Kimani-Murage, Fotso, Ezeh, and Kahurani are with the African Population and Health Research Center, Nairobi, Kenya; Kimani-Murage is with the MRC/Wits Unit in Rural Public Health and Health Transitions Research (Agincourt), School of Public Health, Faculty of Health Sciences, University of the Witwatersrand, Johannesburg, South Africa; Holding is with the Kenya Medical Research Institute, Nairobi, Kenya; Madise is with the Centre for Global Health, Population, Poverty, and Policy, School of Social Sciences, University of Southampton, Southampton, UK; Zulu is with the African Institute for Development Policy (AFIDEP), Nairobi, Kenya.

Correspondence: Elizabeth W. Kimani-Murage, African Population and Health Research Center, P.O. Box 10787, 00100, Nairobi, Kenya. (E-mail: lizmurage@gmail.com; ekimani@aphrc.org)

Nyovani J. Madise and Eliya M. Zulu were formerly of the African Population and Health Research Center, Nairobi, Kenya.

The study was funded by the World Bank (Grant No. 7139065) and the Wellcome Trust (Grant No. 078530/Z/05/Z). 
are a priority as malnutrition is a risk factor for morbidity and mortality, poor cognitive development and reduced productivity. ${ }^{2-4}$ Malnutrition and food insecurity are often instigated by poor crop harvest and lack of financial resources to purchase food at market prices. While weather conditions are a very important factor in determining food insecurity in the agricultural-based rural setting in most of sub-Saharan Africa, lack of stable and well-paying livelihood opportunities is a bigger factor in the cash-based urban setting. Urban malnutrition is an increasing problem, ${ }^{5}$ with $72 \%$ of sub-Saharan Africa's urban residents living in informal settlements characterised by poor environmental and health conditions, limited livelihood opportunities, and a higher prevalence of other health hazards including poor environmental sanitation and HIV/AIDS. ${ }^{6-8}$ Primarily because of the relatively high prevalence of HIV/AIDS-instigated death of adults, the numbers of orphans are rising at a startling rate in sub-Saharan Africa, with every eighth child orphaned. ${ }^{9,10}$ The importance of determining vulnerability to food insecurity and malnutrition among children growing up in poor urban settings is paramount.

A number of factors have been suggested to affect both the level of food security experienced at household level and the children's nutritional status, some of which are independently associated with households in which orphans live. These can broadly be classified into child characteristics (e.g., age and gender), household characteristics (e.g., household income, and number of children in the household), parental characteristics (e.g., occupation, education level and age of the household head) and community factors (e.g., water supply and sanitation). ${ }^{11-16}$ AIDS orphans are particularly vulnerable to food insecurity and malnutrition because of loss of income during the long illness and following death of the deceased parent, ${ }^{17,18}$ and are mostly "adopted" into economically unstable households., ${ }^{919}$ Orphans, for example, tend to live in female-headed households, in larger households and in households headed by the elderly such as grandparents. ${ }^{20}$ Literature also highlights the discrimination against children who are not biologically related to the household head in the allocation of household resources, particularly when those are scarce. ${ }^{21}$

There is considerable variability, however, in vulnerability to adverse nutritional outcomes reported by different studies. ${ }^{22-25}$ This variability may be explained by differences between study populations in the characteristics of the risk experienced and a household's ability to respond to those risks. ${ }^{26}$ Levels of vulnerability are therefore likely to be defined by the interaction between household wealth, the number of risks faced and the specific nature of the orphanhood. ${ }^{18}$ For example, while it is generally accepted that maternal orphans are usually at a greater risk than paternal orphans for health problems, other studies suggest that paternal orphans are more vulnerable to nutritional deficits, demonstrated by low weight-for-height and acute malnutrition (wasting). ${ }^{24,27}$

Given the rapid expansion of urban slums in sub-Saharan Africa, with majority of urban residents living in slum settlements, ${ }^{28}$ their health indicators are likely to determine national indicators. Despite this, little evidence exists regarding food security issues and nutritional outcomes of children growing in these settlements. Additionally, HIV prevalence is highest in urban areas in Kenya $(10 \%)$, almost twice as high as in rural areas $(6 \%)^{7}$ and the prevalence rates in the slums are actually higher than in urban areas in general (14\% in Korogocho and $8 \%$ in Viwandani) ${ }^{*}$. There is need to identify characteristics of the most vulnerable children living in

\footnotetext{
"Preliminary results of an HIV seroprevalence survey conducted between 2007 and 2008 by the African Population and Health Research Centre.
} 
these urban slums in order to devise proper targeting systems. This study seeks to explore the relative vulnerability with regards to food security and nutritional outcomes of vulnerable children and orphans living in urban poor settlements, and to explore the determinants of this vulnerability. We examine both nutritional status and food security so as to ascertain the current situation as well as possible longterm effects of orphanhood.

\section{DATA AND METHODS}

\section{Study Context and Data Source}

This study uses data from a World Bank-funded study of the welfare of orphans and vulnerable children (OVCs) of primary school-going age (6-14 years) in urban poor areas. ${ }^{29}$ The OVC study was carried out in two informal settlements in Nairobi, Kenya, where the African Population and Health Research Centre (APHRC) has run a health and demographic surveillance system, the Nairobi urban health and demographic surveillance system (NUHDSS), since 2001. The NUHDSS, in which the study was nested, involves a systematic quarterly recording of vital demographic events including births, deaths and migrations occurring among household residents. The NUHDSS also regularly collects data on other health and socioeconomic issues such as household assets and amenities, morbidity, and cause of death, using verbal autopsies and education. The two slum areas that comprise the study site (Korogocho and Viwandani) are densely populated (63,318 and 52,583 inhabitants per square kilometer, respectively) and are also characterized by poor housing, high unemployment rates, lack of water supply and sanitation services, high levels of violence and general insecurity and poor health indicators. ${ }^{8,30}$ Viwandani, which is located near the industrial area, has relatively higher levels of education, employment and population mobility, while the population in Korogocho is more stable and with higher levels of co-residence of spouses.

The OVC study, which was carried out between January and June 2007, investigated various domains of child welfare. This paper uses data on nutritional status and food security among orphans and non-orphans. In common with other studies, the term orphan in this study refers to children who have lost either one (paternal/maternal) or both parents (double).

The target minimum sample size calculated for the study was 2,122. We then sought to include all orphans in the NUHDSS database $(n=1,202)$, with an equal number of non-orphans, randomly selected from the NUHDSS database; matched upon age, gender and location of residence at the population level. Hence, the target sample was 2,404 children. Anthropometric measurements (height and weight) were taken from the child; and interviews regarding food security were done with both the child and his/her caregiver.

Ethical approval for the study was obtained from the Kenya Medical Research Institute's National Ethical Review Committee. Written informed consent was obtained from the child's caregiver both for interviewing the caregiver and the child. In addition, verbal assent was obtained from the child.

\section{Study Variables}

Dependent Variables Child nutritional status was derived from anthropometric measurements taken from all the children. All measurements were carried out using standard procedures. ${ }^{31}$ Height was measured using an inelastic tape measure with 
the child standing on level ground against a flat perpendicular surface and was recorded in centimeters to one decimal point. Weight was measured using an electronic scale (Seca 881 U, obtained from United Nations Children's Fund) and was recorded in kilograms to one decimal place. Through use of the World Health Organization (WHO) 2005 Anthro program, ${ }^{32}$ height-for-age and weight-for-age z scores were generated using the 1977 National Center for Health Statistics/World Health Organization (NCHS/WHO) reference. Nutritional outcomes included height-for-age score, weight-for-age score, stunting and underweight.

Food security was measured through complementary interviews with both the caregiver and the index child separately. Questions asked sought to assess perceived hunger, regularity of meals, food access and food shortage. Answers were recoded to be unidirectional, with $0 / 1$ being the poorest/lowest and $4 / 5$ the best/highest; a composite measure was then derived by summing up standardized scores of all responses. Cases with missing information on any of the food security variables were not included in the generation of the composite score (a total of 63 cases). Such missing information was mainly due to questions with reference to a specific date, e.g. if the child was away from the household on the reference day (see Table 7 for questions contributing to the food security score).

Independent Variables The orphan status of children-our key predictor-was defined using two specifications: (1) non-orphan vs. orphan and (2) father/paternal orphan vs. mother/maternal orphan vs. double orphan. Other explanatory variables, mainly extracted from the NUHDSS database, included location of residence (Korogocho, Viwandani); child's age, sex, ethnicity and relationship to the household head; household head's age, sex and highest level of education; number of children $<15$ years in the household; household socioeconomic status (constructed using principal component analysis of the following amenities and assets: electricity supply, bicycle, television, radio, house phone, sofa, table, flush light, kerosene lamp, kerosene stove and wall clock). Household wealth tertiles were generated from the wealth index using the Stata's xtile command and labeled as poorest (lowest 1/3), middle and least poor (highest 1/3).

\section{Statistical Analysis}

Analysis was carried out to test the following hypotheses:

- Orphans are more vulnerable than their non-orphan counterparts in relation to food security and have poorer nutritional status;

- Paternal orphans are worse off than maternal orphans in relation to food security and nutritional outcomes;

- Double orphans are worse off than their paternal and maternal orphan counterparts in relation to food security and nutritional outcomes.

Only children for whom information from two sources (the index child and the caregiver) was captured were considered in the analysis $(n=1,235: 467$ orphans and 768 non-orphans). Five hundred nineteen caregivers were unavailable for interview because of migration (314 permanent, 10 temporary), refusals (48), deaths (17) and untraceable (130). A further 797 children were excluded due to migration (312 permanent and 193 temporary), refusals (44), death (3) and untraceable (245). Overall, there were 1,550 children with a corresponding caregiver interview: 950 non-orphans and 600 orphans. Three hundred fifteen of these children were aged 
TABLE 1 Characteristics of study participants, Nairobi informal settlements, Kenya, 2007

\begin{tabular}{|c|c|c|}
\hline & $n /$ Mean & $\%$ \\
\hline Total participants & 1,235 & 100 \\
\hline \multicolumn{3}{|l|}{ Orphan status } \\
\hline Non-orphan & 768 & 62.2 \\
\hline Orphans & 467 & 37.8 \\
\hline \multicolumn{3}{|l|}{ Orphan type } \\
\hline Paternal & 307 & 24.9 \\
\hline Maternal & 95 & 7.7 \\
\hline Double & 65 & 5.3 \\
\hline \multicolumn{3}{|l|}{ Sex } \\
\hline Male & 579 & 46.9 \\
\hline Female & 656 & 53.1 \\
\hline \multicolumn{3}{|l|}{ Mean age (years) } \\
\hline Total sample & 10.6 & \\
\hline Orphans & 10.8 & \\
\hline Non-orphans & 10.5 & \\
\hline \multicolumn{3}{|c|}{ Household head relationship } \\
\hline Parent & 980 & 79.4 \\
\hline Other relative & 132 & 10.7 \\
\hline Nonrelative & 123 & 10.0 \\
\hline \multicolumn{3}{|l|}{ Ethnicity } \\
\hline Kikuyu & 412 & 33.4 \\
\hline Luhya & 154 & 12.5 \\
\hline Luo & 351 & 28.4 \\
\hline Other & 318 & 25.8 \\
\hline \multicolumn{3}{|c|}{ Sex of household head } \\
\hline Male & 596 & 48.3 \\
\hline Female & 589 & 47.7 \\
\hline Missing & 50 & 4.1 \\
\hline \multicolumn{3}{|c|}{ Age of household head } \\
\hline$<35$ years & 381 & 30.9 \\
\hline $35-49$ years & 588 & 47.6 \\
\hline $50+$ years & 216 & 17.5 \\
\hline Missing & 50 & 4.1 \\
\hline \multicolumn{3}{|c|}{ Mean number of children $<15$ years in the household } \\
\hline Total sample & 3.5 & \\
\hline Orphans & 3.6 & \\
\hline Non-orphans & 3.5 & \\
\hline \multicolumn{3}{|c|}{ Household head education } \\
\hline None & 251 & 20.3 \\
\hline Primary & 707 & 57.3 \\
\hline Secondary+ & 277 & 22.4 \\
\hline
\end{tabular}

15 years or older (due to some time lapse between sampling from the NUHDSS database and the actual study time), and hence excluded from analysis. Thus, 1,235 children were included in the analysis.

The analysis, done using Stata version 10.0 (StataCorp LP, USA), involved both descriptive and multivariate regression methods. Chi-square test was used to test for differences in proportions by orphan status. Initially, mean group differences with regards to nutritional outcomes and food security score were analyzed through $t$ test 
TABLE 2 Caregiver's view on child's food access, food shortage and regularity of meals, Nairobi informal settlements, Kenya, 2007

\begin{tabular}{llllll}
\hline & $\begin{array}{l}\text { Usually } \\
\text { has enough } \\
\text { food (\%) }\end{array}$ & $\begin{array}{l}\text { Had enough } \\
\text { food last } \\
6 \text { months (\%) }\end{array}$ & $\begin{array}{l}\text { Had breakfast } \\
\text { last 2 days (\%) }\end{array}$ & $\begin{array}{l}\text { Had lunch } \\
\text { last 2 days (\%) }\end{array}$ & $\begin{array}{l}\text { Had } \\
\text { supper last } \\
\text { 2 days (\%) }\end{array}$ \\
\hline By orphan status & $p<0.001$ & $p<0.001$ & $p<0.001$ & $p<0.001$ & $p=0.419$ \\
Orphan & 52.4 & 35.2 & 73.9 & 81.3 & 94.2 \\
Non-orphan & 66.1 & 46.3 & 82.9 & 87.8 & 95.3 \\
By orphan type & $p<0.001$ & $p=0.370$ & $p=0.170$ & $p=0.060$ & $p=0.880$ \\
Paternal & 47.4 & 33.2 & 71.1 & 78.9 & 94.3 \\
Maternal & 66.7 & 41.5 & 79.8 & 89.9 & 93.3 \\
Double & 55.4 & 35.4 & 78.7 & 80.7 & 95.2 \\
\hline
\end{tabular}

for orphan status (orphan/non-orphan) and a one-way ANOVA for categories of orphanhood (father, mother and double). Subsequently, random intercepts regression models were used in the multivariate analysis using the Stata's xtmixed command (for linear regression) and xtlogit command (for logistic regression) to allow for clustering at the household level, given the structure of the sample. The 1,235 children included in the study were nested within 1,034 households: 1 household had 4 children, 29 households had 3 children each and 140 households had two children each, while the rest of the 864 households hosted one child each.

TABLE 3 Child's perceived hunger, Nairobi informal settlements, Kenya, 2007

\begin{tabular}{|c|c|c|c|c|}
\hline & Never & Sometimes & Often & Always \\
\hline \multicolumn{5}{|c|}{ Frequency of going to school/staying hungry in the morning (\%) } \\
\hline By orphan status & $p=0.03$ & & & \\
\hline Orphan & 49.3 & 32.7 & 12.3 & 5.8 \\
\hline Non-orphan & 56.4 & 30.5 & 9.8 & 3.4 \\
\hline By orphan type & $p=0.26$ & & & \\
\hline Paternal & 46.2 & 35.1 & 12.8 & 5.9 \\
\hline Maternal & 60.0 & 27.4 & 9.5 & 3.2 \\
\hline Double & 47.7 & 29.2 & 13.9 & 9.2 \\
\hline \multicolumn{5}{|c|}{ Frequency of staying hungry during the day (\%) } \\
\hline By orphan status & $p=0.17$ & & & \\
\hline Orphan & 55.2 & 35.4 & 7.7 & 1.7 \\
\hline Non-orphan & 61.6 & 30.6 & 6.3 & 1.6 \\
\hline By orphan type & $p=0.55$ & & & \\
\hline Paternal & 53.6 & 36.0 & 8.2 & 2.3 \\
\hline Maternal & 61.1 & 30.5 & 8.4 & 0.0 \\
\hline Double & 53.9 & 40.0 & 4.6 & 1.5 \\
\hline \multicolumn{5}{|c|}{ Frequency of sleeping hungry (\%) } \\
\hline By orphan status & $p=0.14$ & & & \\
\hline Orphan & 55.1 & 38.1 & 5.8 & 1.1 \\
\hline Non-orphan & 61.7 & 32.8 & 4.6 & 0.9 \\
\hline By orphan type & $p=0.09$ & & & \\
\hline Paternal & 52.1 & 39.3 & 7.5 & 1.0 \\
\hline Maternal & 67.4 & 29.5 & 2.1 & 1.1 \\
\hline Double & 50.8 & 44.6 & 3.1 & 1.5 \\
\hline
\end{tabular}


TABLE 4 Mean unadjusted height-for-age, weight-for-age and weight-for-height $z$ scores, and prevalence of malnutrition, Nairobi informal settlements, Kenya, 2007

\begin{tabular}{llllll}
\hline & Food security score & HAZ & WAZ & Stunting (\%) & Underweight (\%) \\
\hline By orphan status & $p<0.001$ & $p=0.242$ & $p=0.009$ & $p=0.770$ & $p=0.670$ \\
Orphans & -1.46 & -1.16 & -0.93 & 25.1 & 12.5 \\
Non-orphans & 0.84 & -1.25 & -1.07 & 25.8 & 13.3 \\
By orphan type & $p=0.007$ & $p=0.119$ & $p=0.029$ & $p=0.700$ & $p=0.840$ \\
Paternal & -2.21 & -1.17 & -0.90 & 24.1 & 13.1 \\
Maternal & 0.61 & -1.34 & -1.13 & 28.4 & 11.6 \\
Double & -0.96 & -0.88 & -0.75 & 24.6 & 10.8 \\
\hline
\end{tabular}

HAZ height for age, WAZ weight for age

The mixed effect model was used to account for both fixed effects and random effects at the child level and at the household level, respectively.

\section{RESULTS}

\section{Children's Background Characteristics}

Table 1 presents characteristics of the 1,235 children included in the analysis. Given that there were a higher number of orphans living in Korogocho, compared to Viwandani, our sampling strategy yielded about three-quarters of children from Korogocho. The sample was made up of 768 non-orphans $(62.2 \%)$ and 467 orphans $(37.8 \%)$, with a predominance of paternal orphans (about $66 \%$ of the orphans). The mean age of children was 10.6 years, with $53 \%$ girls.

\section{FOOD SECURITY}

According to the caregiver responses, orphans had poorer access to food in the last 6 months $(p<0.001)$, as shown in Table 2. A smaller proportion of orphans compared to non-orphans reported usually having enough food $(p<0.001)$, with paternal orphans being the worst off among the orphan types $(p<0.001)$. The caregiver's reports also show that orphans also took fewer meals on a daily basis than non-orphans $(p<0.001)$ (results not shown on the table). A smaller proportion of orphans were said to have had breakfast or lunch at least once in the last 2 days $(p<0.001$, respectively) (Table 2$)$. With regards to child responses, a higher proportion of orphans than non-orphans reported staying hungry in the morning or going to school hungry $(p=0.030)$, which tallies with the caregiver's response on frequency of the child taking breakfast in the last 2 days (Table 3 ).

Orphans had a significantly lower mean food security score compared to nonorphans $(p<0.001)$. (Table 4$)$ The means for paternal, maternal and double orphans were also significantly different, with paternal orphans being the most vulnerable $(p=0.007)$.

\section{Nutritional Status}

Unadjusted nutritional outcomes by orphan status and orphan types are shown in Table 4. Higher $z$ scores denote better nutritional outcomes. The proportion of children that were stunted was $26 \%$. There was no significant variation in the prevalence of stunting by orphan status or orphan type. There was also no 


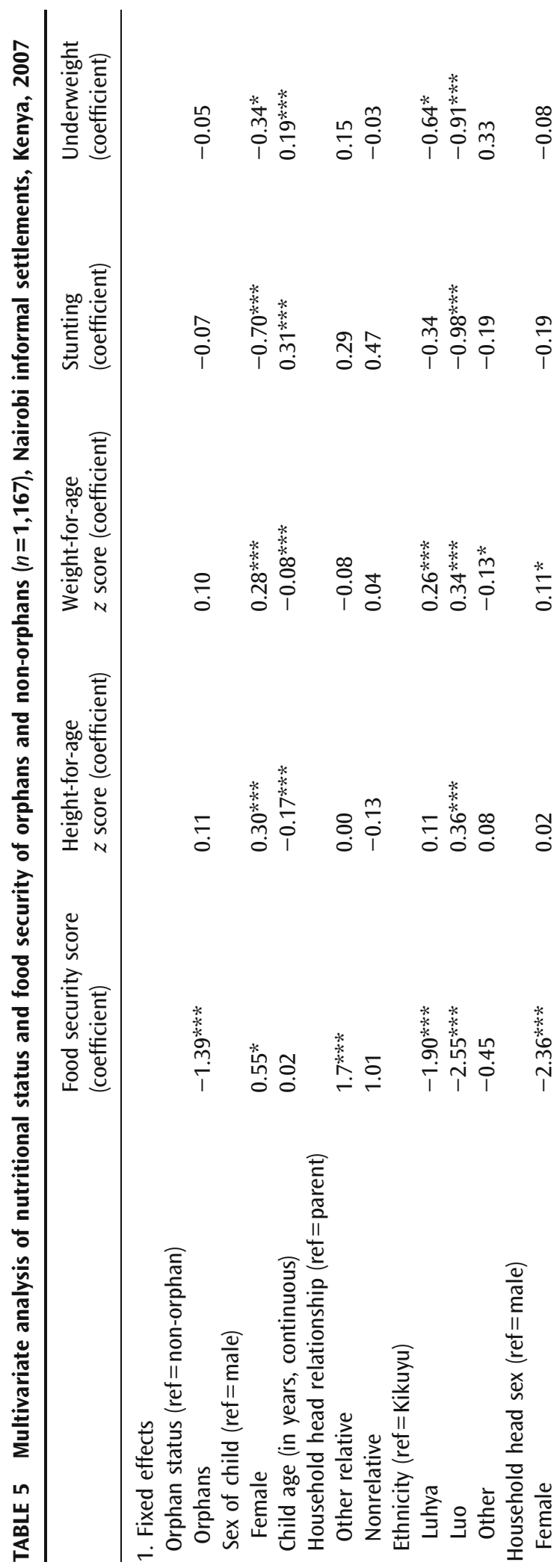




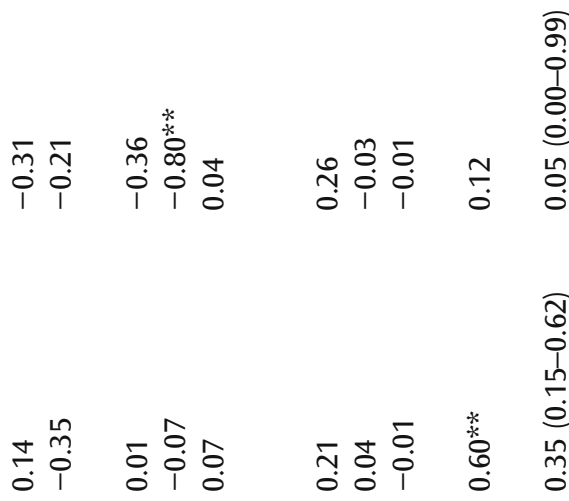

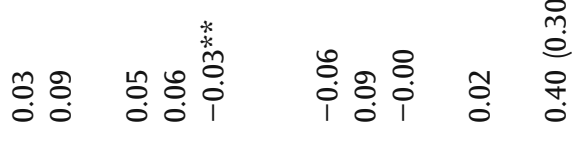

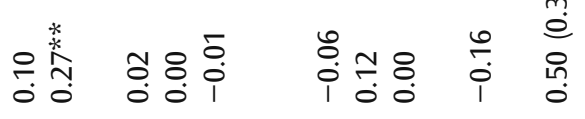

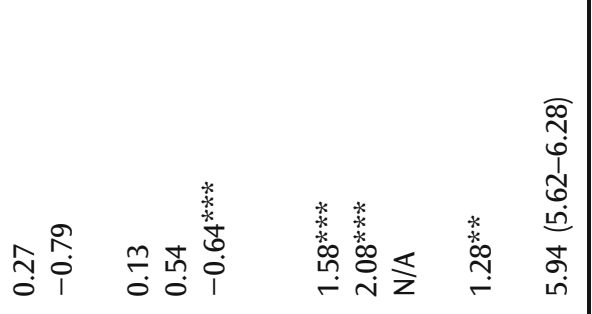

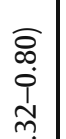




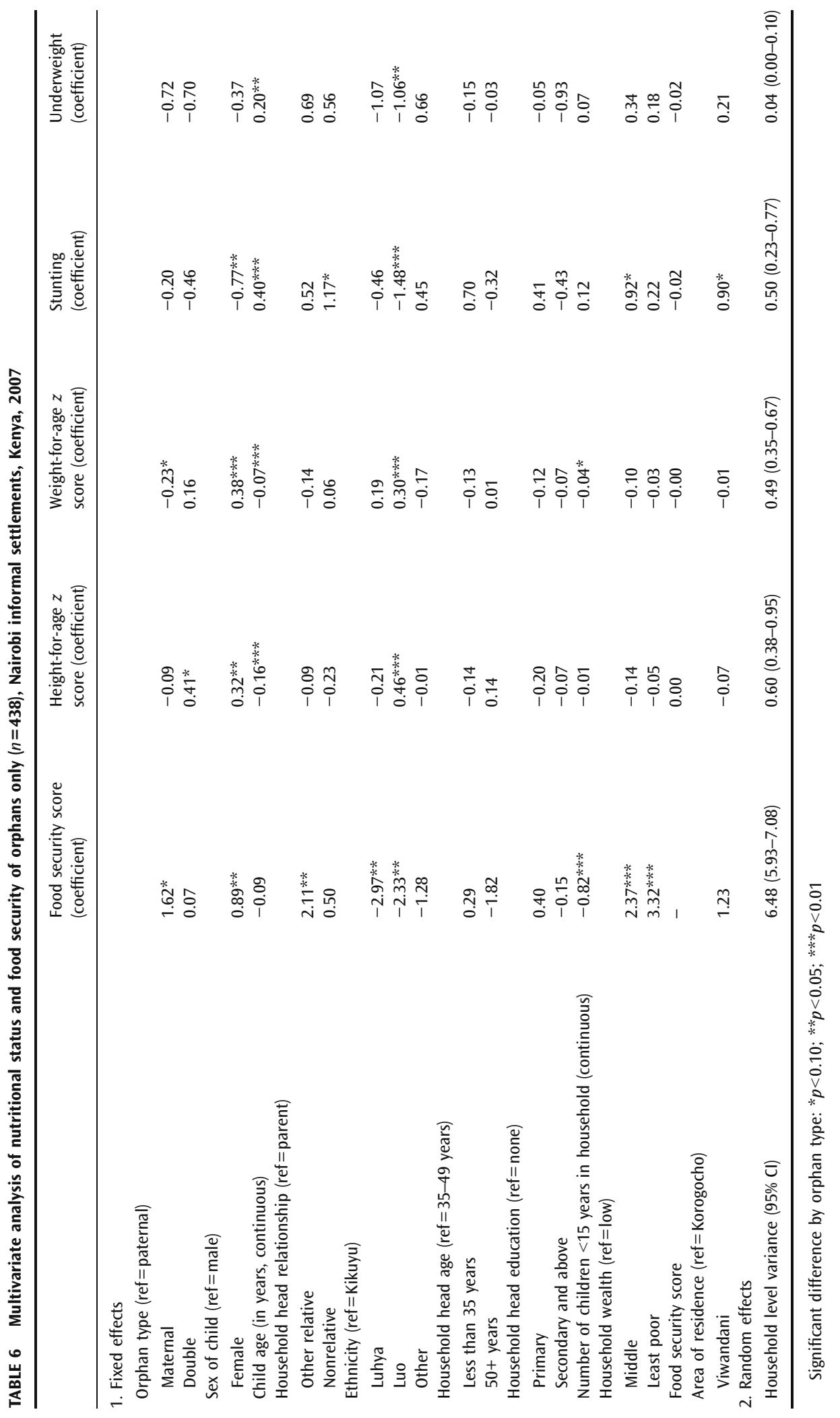


significant variation in height-for-age $z$ scores by orphan status or orphan type. The total proportion of underweight children was $13 \%$. There was no significant variation in the prevalence of underweight by orphan status or orphan type. With regards to weight-for-age scores, orphans were significantly better off than nonorphans $(p=0.009)$. Among orphaned children, maternal orphans showed the worst outcome $(p=0.029)$.

\section{Multivariate Results: Orphans vs. Non-Orphans}

Table 5 shows results of multivariate regression analysis performed on the total sample of children, with orphan status coded as binary (non-orphan, orphan). In terms of height for age, girls had significantly higher $z$ scores (better outcomes) than boys $(p<0.01)$, younger children were significantly better off than their older counterparts $(p<0.01)$, children of Luo ethnic group had significantly higher $z$ scores compared to Kikuyu children $(p<0.01)$, while children with household heads aged $50+$ years had significantly higher $z$ scores compared to those with household heads aged 35-49 years $(p<0.01)$. With regards to weight-for-age $z$ scores, girls had significantly higher $z$ scores than boys $(p<0.01)$; Luhya and Luo children had significantly higher $z$ scores than Kikuyu children $(p<0.01)$, while children of other ethnic groups had significantly lower $z$ scores $(p<0.01)$; children of female-headed households had higher scores than of male-headed households $(p<0.1)$, while households with a higher number of children aged less than 15 years had significantly lower $z$ scores $(p<0.01)$.

For stunting, girls and Luo children were significantly less stunted $(p<0.01)$, while older children $(p<0.01)$ and children in Viwandani $(p<0.05)$ were significantly more stunted. Likewise, girls $(p<0.1)$, Luhya $(p<0.1)$ and Luo $(p<0.01)$ children, and children whose household heads had secondary education $(p<0.05)$ were less underweight, while older children were more underweight $(p<0.01)$.

The pattern of association of the covariates with food security was different from that observed for nutritional status in a number of respects. Orphans had significantly poorer food security $(p<0.01)$, girls had better food security $(p<0.1)$, children whose household head was a relative other than the parent had significantly better food security $(p<0.01)$, Luhya and Luo children had significantly poorer food security compared to Kikuyu children $(p<0.01$, respectively), children in femaleheaded households had significantly poorer food security $(p<0.01)$, while the number of children aged $<15$ years in the household was significantly negatively associated with food security $(p<0.01)$. Differentials in food security by household wealth were large, strong and in the expected direction $(p<0.01)$; and Viwandani children displayed significantly better outcomes than their counterparts from Korogocho $(p<0.05)$.

\section{Multivariate Result by Orphan Type}

Table 6 shows the analysis restricted to the sample of orphans, with orphan types defined as paternal (reference category), maternal or double. Double orphans tended to have better nutritional and food security outcomes, compared with paternal orphans, but differences were generally not significant. Maternal orphans were worse off than paternal orphans in terms of height for age (difference not significant) and weight for age $(p<0.1)$. In contrast, maternal orphans were better off than the paternal orphans in terms of food security $(p<0.1)$. Covariates for nutritional outcomes and food security among orphans were generally similar to those described above among all children. 
Household-level random variation was significant for the various outcomes, indicating significant intrahousehold heterogeneity in nutritional outcomes and food security.

\section{DISCUSSION}

In line with previous studies, ${ }^{26,33}$ our results indicate that orphans living in households in informal settlements in Nairobi are indeed more vulnerable with regards to food security than non-orphaned children, most particularly paternal orphans. This may be as a consequence, as found in other studies, of the loss of the main income earner, ${ }^{20}$ an explanation that is consistent with the association found between household socioeconomic status and food security.

In contrast, we found no significant effect of orphanhood on nutritional status, but this too has been observed elsewhere. ${ }^{23-25,33}$ The difference between orphans and non-orphans with regards to food security did not therefore translate into detrimental effects upon nutritional status, with food security not emerging as an important determinant of nutritional status in the regression analysis. The discrepancy in the relationship between orphanhood and food security scores and nutritional status was most marked for maternal orphans, who had the highest scores in food security while having the poorest nutritional outcomes. Reflected in the differences in food security may be differences in perceived vulnerability rather than functional differences in food access and intake. Alternatively, the discrepancies may reflect the immediacy of changes in food security, while children's weight and, to a greater degree, height reflect past access and adequacy of intake. Early growth trajectories may have predated the onset of the influence of parental illness and death, and thus height and weight and the respective stunting and underweight may not be the most sensitive indicators of current influences on nutritional status. The lack of a strong association between household socioeconomic status and nutritional status also suggests that current household characteristics do not strongly influence current nutritional status.

Differential vulnerability between orphan groups was found in our study, a common feature of other investigations. ${ }^{24,27}$ Contrary to our expectations, we did not find double orphans as the most vulnerable. In our study, paternal orphans had the lowest scores for food security. It may be that adoption into other households protects the double orphan from risks experienced by households where the father has died and the mother remains with the sole responsibility for feeding her children. This was also reflected in children and orphans living in households headed by a relative other than the parent having higher food security scores. The relative resilience of those in households where the mother has died reflects the critical importance of a stable breadwinner (mostly the man) in the urban context. When he dies, the presence of the mother alone is not adequate to cater for the children. When the mother dies, however, the man is likely to have another wife or another female relative help to take care of the children. Alternatively, the poorer food security scores of paternal orphans may reflect the greater anxiety experienced by those in female-headed households. To answer the questions about differential vulnerability, more information is needed about support networks available to different households than is currently presented in the literature.

Factors, other than orphan status, that we found to have contributed to differences in food security and nutritional outcomes include sex, age and ethnicity of the child; household head's relationship to the child; sex, age and education level 
of the household head; number of dependants in the household; household socioeconomic status; and area of residence. At the child level, we found that, in common with some but not all other studies, ${ }^{11,13,34,35}$ males were more vulnerable to poorer nutritional outcomes and were more vulnerable to food insecurity. The relative vulnerability of males to malnutrition has been associated with low socioeconomic status. ${ }^{36}$ The observed sex difference in nutritional status may also be due to a delay in pubertal growth spurt among adolescent boys in our study, common where undernutrition is prevalent. ${ }^{37}$ Contrary to some other studies, ${ }^{24}$ younger children were less vulnerable, possibly because this study focused on school-age children, and not the very young. While studies have indicated that growth of young children $(<10$ years $)$ is similar across different ethnic backgrounds, ${ }^{38}$ this may not apply for older children. The ethnic differences observed may be more related to genetic make-up rather than to food access, as the ethnic groups with best nutritional outcomes had the lowest food security score, temporal limitations notwithstanding.

At the household level, that the number of resident children was associated with higher food insecurity is not unexpected, ${ }^{12,15}$ and does highlight the need to restrict the burden of numbers on households providing support for orphans. Children in female-headed households had lower food security scores which may reflect lower socioeconomic status, particularly in circumstances of death of the bread earner. Education of the household head, which may relate to socioeconomic status and food security, was associated with better nutritional outcomes, ${ }^{29}$ suggesting a more consistent nutritional intake in this group of children over time. Better nutritional outcomes also seem to characterise children living in Korogocho, the more stable of the two neighbourhoods, although better food security was experienced by children living in the slightly richer neighbourhoods of Viwandani. It is possible that the differences in nutritional outcomes may also be due to ethnic distribution as results not shown indicate that there were more children of Luo ethnic group in Korogocho (about double) than in Viwandani (while Luos had the best nutritional outcomes). The significant household-level random effects found imply that there are other influences upon variability in outcome that we have not captured in this study.

A few limitations of the study are worth mentioning. We were unable to ascertain whether those large numbers of children missing through migration and other reasons were also from significantly different, perhaps more vulnerable groups. Given the extended family system of this region, it is likely that they will have been fostered into the households of relatives resident in other areas, and our data suggest that the specific characteristics of those communities will have had a different impact upon outcome. While designed for use within the target population, the food security assessment measure used did not include the multiple dimensions of food security used by measures developed in other cultural settings, limiting the depth of our analysis. A longitudinal design would be able to address the uncertainty over whether the poorer scores of orphans on our measure of food security were due to functional differences between households or to differences in the perception of difficulties in food access that might be, for example, caused by the stress and anxiety of the illness/death of the child's parents.

Nonetheless, we were able to conclude that orphans are more vulnerable to food insecurity but not nutritional status. The results also show that the most vulnerable children are boys, those living in households with lowest socioeconomic status, with many dependants, and headed by women and adults with low human capital (low education). Taken together, the results indicate that the vulnerability of children 
living in poor households to the effects of orphanhood should be understood in terms of the constellation of risk and resilience factors that they are exposed to, and not to a single negative event, i.e., the death of a parent. The differential vulnerability among different orphan groups suggests that both future investigations and interventions should no longer consider all orphans as one group, but consider the type of loss as a more sensitive indicator of need.

\section{ACKNOWLEDGEMENTS}

This study was funded by the World Bank (Grant No. 7139065) and Wellcome Trust (Grant No. 078530/Z/05/Z). We also acknowledge funding for the NUHDSS from the Rockefeller Foundation and core support for APHRC from the Rockefeller Foundation, the William and Flora Hewlett Foundation and the Wellcome Trust. We would like to thank Dr. Adama Konseiga and Dr. Johannes John-Langba formerly of the APHRC for their input in the conception and design of the project. We acknowledge technical advice from Dr. Ousmane Faye, formerly of the APHRC, and Dr. Shane Norris of the University of the Witwatersrand, South Africa. We thank the data collection team and the data processing and management team at the APHRC for their contribution. We are highly indebted to the study participants.

\section{APPENDIX}

TABLE 7 Questions contributing to food security score, Nairobi informal settlements, Kenya, 2007

\begin{tabular}{|c|c|c|}
\hline Question & Measurement scale & $\begin{array}{l}\text { Questionnaire/ } \\
\text { Respondent }\end{array}$ \\
\hline $\begin{array}{l}\text {-Would you say the child usually } \\
\text { has enough to eat? }\end{array}$ & Binary (yes/no) & Caregiver \\
\hline $\begin{array}{l}\text {-How many meals does the child usually } \\
\text { have/eat every day? }\end{array}$ & $\begin{array}{l}3 \text { (Quantitative, } \\
\text { more than three } \\
\text { was recoded as } 3 \text { ) }\end{array}$ & Caregiver \\
\hline $\begin{array}{l}\text {-How many times did the child eat yesterday } \\
\text { and the day before yesterday? (Did s/he } \\
\text { eat... yesterday, day before yesterday? } \\
\text { Breakfast } \\
\text { Lunch } \\
\text { Supper }\end{array}$ & Binary (yes/no) & Caregiver \\
\hline $\begin{array}{l}\text {-In the past } 6 \text { months, how often has the } \\
\text { child not had enough to eat? Was it every day, a few } \\
\text { times a week, a few times a month, once a month } \\
\text { or less, or you always had enough to eat? }\end{array}$ & 5 & Caregiver \\
\hline $\begin{array}{l}\text {-How often would you say that you go to school } \\
\text { hungry/you stay hungry in the morning (Is it } \\
\text { every day, often, sometimes or never)? }\end{array}$ & 4 & Child \\
\hline $\begin{array}{l}\text {-How often would you say that you stay hungry during } \\
\text { the day (Is it every day, often, sometimes or never)? }\end{array}$ & 4 & Child \\
\hline $\begin{array}{l}\text {-How often would you say that you sleep hungry } \\
\text { (Is it every day, often, sometimes or never)? }\end{array}$ & 4 & Child \\
\hline
\end{tabular}




\section{REFERENCES}

1. United Nations. The Millennium Development Goals Report. New York: United Nations; 2008.

2. Black RE, Allen LH, Bhutta ZA, et al. Maternal and child undernutrition: global and regional exposures and health consequences. Lancet. 2008; 371(9608): 243-260.

3. Victora CG, Adair L, Fall C, et al. Maternal and child undernutrition: consequences for adult health and human capital. Lancet. 2008; 371(9609): 340-357.

4. Grantham-McGregor S, Cheung YB, Cueto S, et al. Developmental potential in the first 5 years for children in developing countries. Lancet. 2007; 369(9555): 60-70.

5. Fotso JC. Urban-rural differentials in child malnutrition: trends and socioeconomic correlates in sub-Saharan Africa. Health Place. 2007; 13(1): 205-223.

6. Kimani-Murage EW, Ngindu AM. Quality of water the slum dwellers use: the case of a Kenyan slum. J Urban Health. 2007; 84(6): 829-838.

7. Central Bureau of Statistics (CBS) [Kenya] MoHMK, ORC Macro. Kenya Demographic and Health Survey 2003: Key Findings. Calverton, Maryland, USA: CBS, MOH and ORC Macro; 2004. Available at: http://www.measuredhs.com. accessed August 2009.

8. African Population and Health Research Center. Health and Livelihood Needs of Residents of Informal Settlements on Nairobi City. Occasional Study Report 1. Nairobi: APHRC; 2002. Available at http://www.aphrc.org; accessed 2009.

9. UNICEF. Africa's Orphaned Generation. New York: UNICEF; 2003. Available at: www. unicef.org/media/media_16664.html; Accessed June 2009.

10. Bicego G, Rutstein S, Johnson K. Dimensions of the emerging orphan crisis in subSaharan Africa. Soc Sci Med. 2003; 56:(6)1235-1247.

11. Kabubo-Mariara J, Ndenge GK, Mwabu DK. Determinants of children's nutritional status in Kenya: evidence from demographic and health surveys. J Afr Econ. 2008; doi: 10.1093/jae/ejn024.

12. Hien NN, Kam S. Nutritional status and the characteristics related to malnutrition in children under five years of age in Nghean, Vietnam. J Prev Med Public Health. 2008; 41(4): 232240.

13. Wamani H, Astrom AN, Peterson S, Tumwine JK, Tylleskar T. Boys are more stunted than girls in sub-Saharan Africa: a meta-analysis of 16 demographic and health surveys. BMC Pediatr. 2007; 7: 17.

14. Pongou R, Ezzati M, Salomon JA. Household and community socioeconomic and environmental determinants of child nutritional status in Cameroon. BMC Public Health. 2006; 6: 98.

15. Silva P. Environmental Factors and Children's Malnutrition in Ethiopia. Washington D.C: World Bank; 2005.

16. Toyama N, Wakai S, Nakamura Y, Arifin A. Mother's working status and nutritional status of children under the age of 5 in urban low-income community, Surabaya, Indonesia. J Trop Pediatr. 2001; 47(3): 179-181.

17. Madhavan S, Townsend N. The social context of children's nutritional status in rural South Africa. Scand J Public Health. 2007; 35(Suppl 69): 107-117.

18. Haddad L, Gillespie S. Effective food and nutrition policy responses to HIV/AIDS: what we know and what we need to know. J Int Dev. 2001; 13(4): 487-511.

19. Case A, Paxson C, Ableidinger J. Orphans in Africa: parental death, poverty and school enrolment. Demography. 2004; 41(3): 483-508.

20. Monasch R, Boerma JT. Orphanhood and childcare patterns in sub-Saharan Africa: an analysis of national surveys from 40 countries. AIDS (London, England). 2004; 18(Suppl 2): S55-65.

21. Nhate V, Arndt C, Barslund M, Van den Broeck K. Orphans and Discrimination in Mozambique: An Outlay Equivalence Analysis. Washington, DC: IFPRI; 2005. Available at: http://www.ifpri.org/themes/hiv/pdf/arndtetal2005.pdf; Accessed July 2009. 
22. Ainsworth M, Semali I. The impact of adult deaths on children's health in northwestern Tanzania. Washington, DC: 2000. World Bank Policy Research Working Paper 2266, 28. Available at: http://econ.worldbank.org; Accessed August 2009.

23. Sarker M, Neckermann C, Muller O. Assessing the health status of young AIDS and other orphans in Kampala, Uganda. Trop Med Int Health. 2005; 10(3): 210-215.

24. Lindblade KA, Odhiambo F, Rosen DH, DeCock KM. Health and nutritional status of orphans $<6$ years old cared for by relatives in western Kenya. Trop Med Int Health. 2003; 8(1): 67-72.

25. Crampin AC, Floyd S, Glynn JR, et al. The long-term impact of HIV and orphanhood on the mortality and physical well-being of children in rural Malawi. AIDS. 2003; 17(3): 389-397.

26. Greenblott K, Greenaway K. Food Security and Nutrition: Meeting the Needs of Orphans and Other Children Affected by HIV and AIDS in Africa: Report for WFP/UNICEF. Rome: WFP; 2007. Available at: http://www.wfp.org/food_aid/doc/Food_Security_and_ Nutrition_Meeting.pdf; Accessed June 2009.

27. Chilima DM. Relief and Recovery Operation (PRRO): Integrated Support to HIV/AIDS Infected and Affected People in Eight Districts of Malawi: Baseline Survey Final Report. Lilongwe: WFP; 2006.

28. UNHABITAT. Slums of the World: The Face of Urban Poverty in the New Millennium?. Nairobi: UNHABITAT; 2003. Available at: http://www.unhabitat.org; Accessed June 2009.

29. African Population and Health Research Center and the World Bank. The Plight of Orphans and Vulnerable Children in Nairobi Urban Slums in the Face of HIVIAIDS. APHRC and the World Bank; 2007.

30. African Population and Health Research Center. Population and Health Dynamics in Nairobi Informal Settlements. Nairobi: APHRC; 2002. Available at: http://www.aphrc. org; Accessed August 2009

31. Rosalind SG. Principles of nutritional assessment. 2nd ed. New York: Oxford University Press; 2005.

32. World Health Organization. WHO Anthro 2005, Beta version Feb 17th, 2006: Software for assessing growth and development of the world's children. Geneva: WHO; 2006. Available at: http://www.who.int/childgrowth/software/en/; Accessed August 2009.

33. Rivers J, Silvestre E, Mason J. Nutritional and food security status of orphans and vulnerable children: a report of a research project supported by UNICEF, IFPRI, and WFP. New Orleans: Department of International Health and Development, Tulane University School of Public Health and Tropical Medicine; 2004.

34. Kimani-Murage EW, Kahn K, Pettifor JM, et al. The prevalence of stunting, overweight and obesity, and metabolic disease risk in rural South African children. BMC Public Health. 2010; 10(1): 158.

35. Strauss J. Households communities and preschool children's nutrition outcomes: evidence from rural Côte d'Ivoire. Econ Devel Cult Change. 1990; 38(2): 231-262.

36. Wamani H, Tylleskar T, Astrom AN, Tumwine JK, Peterson S. Mothers' education but not fathers' education, household assets or land ownership is the best predictor of child health inequalities in rural Uganda. Int J Equity Health. 2004; 3(1): 9.

37. Sedlmeyer IL, Palmert MR. Delayed puberty: analysis of a large case series from an academic center. Clin Endocrinol Metab. 2002; 87(4): 1613-1620.

38. Habicht J, Martorell R, Yarbrough C, Malina R, Klein R. Height and weight standards for preschool children. How relevant are ethnic differences in growth potential? Lancet. 1974; 1(7858): 611-614.

39. El Taguri A, Betilmal I, Mahmud SM, et al. Risk factors for stunting among under-fives in Libya. Public Health Nutr. 2009; 12(8): 1141-1149. 